\title{
Publisher Correction: Global ecological impacts of marine exotic species
}

Andrea Anton (D), Nathan R. Geraldi D, Catherine E. Lovelock, Eugenia T. Apostolaki (D), Scott Bennett, Just Cebrian, Dorte Krause-Jensen, Nuria Marbà (D), Paulina Martinetto, John M. Pandolfi (D), Julia Santana-Garcon (D) and Carlos M. Duarte (iD)

Correction to: Nature Ecology \& Evolution https://doi.org/10.1038/s41559-019-0851-0 (2019); published online 8 April 2019.

In the HTML version of this Article originally published, the numerical values for effect size given on the right-hand side of Fig. 5 were missing minus signs for the top 11 species (Hemigrapsus sanguineus to Codium fragile). The left side of the effect size axis label was also missing the minus signs. These errors have now been corrected. The PDF was unaffected.

Published online: 2 August 2019

https://doi.org/10.1038/s41559-019-0965-4 